\title{
Conventional doped silica/fluoride glass fibers for low loss and minimum dispersion effects
}

\author{
Aadel M. Alatwi ${ }^{1}$, Ahmed Nabih Zaki Rashed ${ }^{2}$ \\ ${ }^{1}$ Electrical Engineering Department, Faculty of Engineering, Tabuk University, Tabuk, Saudi Arabia \\ ${ }^{2}$ Electronics and Electrical Communications Engineering Department, Faculty of Electronic Engineering, \\ Menoufia University, Menouf, Egypt
}

\begin{tabular}{l} 
Article Info \\
\hline Article history: \\
Received Mar 30, 2020 \\
Revised Jun 29, 2020 \\
Accepted Jul 19, 2020 \\
\hline
\end{tabular}

\section{Keywords:}

Aluminum fluoride fibers

Doped silica fibers

Low loss

Minimum dispersion

\begin{abstract}
This paper has clarified the conventional silica doped (SiGeO2) and aluminum fluoride (AlF3) fibers for low loss and minimum dispersion effects for upgrading fiber-optic communication systems. The total dispersion with the total losses are modeled for both fibers. Fiber bandwidth and the power received are estimated based on different dopant ratios. The spectral and thermal effects are applied on both fibers. The study assured the negative effects of increasing ambient temperatures and the positive effects of increasing dopant ratios on the performance of the fibers.
\end{abstract}

This is an open access article under the CC BY-SA license.

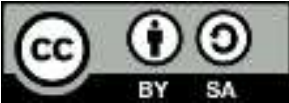

\section{Corresponding Author:}

Ahmed Nabih Zaki Rashed

Faculty of Electronic Engineering

Menoufia University, Menouf 32951, Egypt

E-mail: zakirashed73355@gmail.com

\section{INTRODUCTION}

The power of the transmitted signal is considered due to the disturbances that accompany the transmission and reception of the signal (electronic noise, interference, etc.). Receivers may not detect and demodulate input signals with a power lower than a minimum level [1-9] called the sensitivity of the receiver. Further specifications, which affect the quality of service, are given in terms of signal-to-noise rate and bit error rate [10-14]. All these impose a lower limit to the minimum power that can be received [15-19]. Once the characteristics of attenuation on physical media and the sensitivity of the receiver are known, the limitation on the received power results in a limitation on the maximum distance that the link is capable of supporting (assigned the maximum power that the transmitter can provide). One way of summarizing the two issues just mentioned, the spectral efficiency and energy of a given transmission system, is to introduce a measure of overall efficiency given by the product between the maximum transmission rate obtained over a half with a given technique modulation and the maximum distance [20-25].

\section{MODEL DESCRIPTION AND RESEARCH METHOD}

The total fiber dispersion factor can be modeled by the following equation $[1-4,26]$ : 
$\mathrm{D}_{\mathrm{T}}=-\frac{\lambda}{c} \frac{d^{2} n_{\text {core }}}{d \lambda^{2}}-\frac{\Delta n n_{\text {core }}}{c \lambda}\left(\frac{n_{\text {eff }}}{n_{\text {core }}}\right)^{2} M(V)$

The relative refractive index difference and the normalized frequency can be estimated by $[2,3,5-8,27]$ :

$$
\begin{aligned}
& \Delta n=\left(\frac{n_{\text {core }}-n_{\text {clad }}}{n_{\text {core }}}\right) \\
& V=2 \pi a \sqrt{n_{\text {core }}{ }^{2}-n_{\text {clad }}^{2}} \\
& M(V)=0.8+0.549(2.834-V)^{2} \text { for silica doped fiber } \\
& M(V)=1.34+0.056(9.543-0.5 V)^{2} \text { for Fluoride fiber }
\end{aligned}
$$

where a is fiber core radius, $\mathrm{n}_{\text {core }}$ is core refractive index, $\mathrm{n}_{\text {clad }}$ is the clad refractive index $[9-12,26,27]$.

$$
n_{\text {core }}^{2}=1+\frac{S_{1} \lambda^{2}}{\lambda^{2}-B_{1}^{2}}+\frac{S_{2} \lambda^{2}}{\lambda^{2}-B_{2}^{2}}+\frac{S_{3} \lambda^{2}}{\lambda^{2}-B_{3}^{2}}
$$

$$
\begin{aligned}
& \text { With } \mathrm{S}_{1}=0.6961+0.1107 \mathrm{x}, \mathrm{S}_{2}=0.4079+0.3102 \mathrm{x}, \mathrm{S}_{3}=0.8974-0.0433 \mathrm{x} \\
& \mathrm{B}_{1}=0.068+0.0005 \mathrm{x}, \mathrm{B}_{2}=0.116+0.0377 \mathrm{x}, \mathrm{B}_{3}=9.896+1.94577 \mathrm{x}
\end{aligned}
$$

the first and second differentiation with respect to wavelength can be estimated by the following equations:

$$
\begin{aligned}
& \frac{d n_{\text {core }}}{d \lambda}=\frac{-\lambda}{n_{\text {core }}}\left(\frac{S_{1} B_{1}^{2}}{\left(\lambda^{2}-B_{1}^{2}\right)^{2}}+\frac{S_{2} B_{2}^{2}}{\left(\lambda^{2}-B_{2}^{2}\right)^{2}}+\frac{S_{3} B_{3}^{2}}{\left(\lambda^{2}-B_{3}^{2}\right)^{2}}\right), \\
& \frac{d^{2} n_{\text {core }}}{d \lambda^{2}}=\frac{1}{n_{\text {core }}}\left(\frac{S_{1} B_{1}^{2}\left(3 \lambda^{2}+B_{1}^{2}\right)}{\left(\lambda^{2}-B_{1}^{2}\right)^{3}}+\frac{S_{2} B_{2}^{2}\left(3 \lambda^{2}+B_{2}^{2}\right)}{\left(\lambda^{2}-B_{2}^{2}\right)^{3}}+\frac{S_{3} B_{3}^{2}\left(3 \lambda^{2}-B_{3}^{2}\right)}{\left(\lambda^{2}-B_{3}^{2}\right)^{3}}-\left(\frac{d n_{\text {core }}}{d \lambda}\right)^{2}\right),
\end{aligned}
$$

where the effective refractive index of the fiber core is given by $[7,9,12]$ :

$$
n_{\text {eff }}=n_{\text {core }}-\lambda \frac{d n_{\text {core }}}{d \lambda}
$$

For aluminum fluoride glass fibers, fiber core refractive index as a function of the wavelength is modeled by $[7,13,14,26,27]$ :

$$
n=\frac{A}{\lambda^{4}}+\frac{B}{\lambda^{2}}+C+D \lambda^{2}+E \lambda^{4}
$$

$\mathrm{A}=9.37 \times 10^{-5}, \mathrm{~B}=2.94 \times 10^{-3}, \mathrm{C}=1.49, \mathrm{D}=-0.00125$, and $\mathrm{E}=-4 \times 10^{-6}$, where the fiber losses for both silica doped and fluoride glass fibers are given by $[1,2,5,13-15,26,27]$ :

$$
\begin{aligned}
& \alpha=A_{m} e^{b_{m} \lambda}+\frac{C_{m}}{\lambda^{4}}+D_{m} e^{-d_{m} \lambda} \\
& \mathrm{A}_{\mathrm{m}}=0.0132 \quad \mathrm{x} /(1+733 \quad \mathrm{x}), \quad \mathrm{b}_{\mathrm{m}}=4.8\left(\frac{T_{o}}{T}\right), \quad \mathrm{C}_{\mathrm{m}}=\left(\begin{array}{lll}
0.74+66 & \Delta \mathrm{n}
\end{array}\right)\left(\frac{T_{o}}{T}\right), \quad \mathrm{D}_{\mathrm{m}}=4.9 \times 10^{11}, \quad \mathrm{~d}_{\mathrm{m}}=48\left(\frac{T_{o}}{T}\right)
\end{aligned}
$$


for silica doped

$$
\mathrm{A}_{\mathrm{m}}=0, \mathrm{~b}_{\mathrm{m}}=0, \mathrm{C}_{\mathrm{m}}=0.6 \mathrm{y}\left(\frac{T_{o}}{T}\right), \mathrm{D}_{\mathrm{m}}=1.2167 \times 10^{10}, \mathrm{~d}_{\mathrm{m}}=71.64 \mathrm{y}^{2}\left(\frac{T_{o}}{T}\right) \text { for Fluoride fiber }
$$

where $\mathrm{T}$ is temperature, $\mathrm{T}_{0}$ is room temperature, and $\mathrm{x}$ is the germanium dopant ratio. The fiber bandwidth can be given by the mathematical relation $[1-3,5,8,10,26,27]$ :

$$
\mathrm{BW}_{\mathrm{F}}=0.44 / \mathrm{T}_{\min }
$$

where the minimum pulse broadening due to the dispersion factor is given by $[3,5,8,12,15,26,27]$ :

$$
\mathrm{T}_{\min .}=\mathrm{D}_{\mathrm{T}} \mathrm{L} \Delta \lambda
$$

where $\mathrm{L}$ is the fiber length in $\mathrm{km}, \Delta \lambda$ is the spectral linewidth of the light source. In addition to the received power can be estimated by the following formula $[2,4,9,12,15,26]$ :

$$
P_{R}=P_{T} \exp (-\alpha L)
$$

The loss power percentage can be given by the mathematical relation:

$$
P_{(\text {Loss })}(\%)=\frac{P_{T}-P_{R}}{P_{R}} \times 100 \%
$$

\section{PERFORMANCE ANALYSIS WITH DISCUSSIONS}

The silica doped and aluminum fluoride fibers have been mathematically analyzed in detail. The total fiber losses and dispersion have been modeled to estimate the fiber bandwidth. The total pulse broadening due to dispersion is analyzed and estimated to evaluate the fiber bandwidth. The received power is evaluated based on the mathematical analysis of the total fiber losses. The performance key parameters are estimated based on the clarified variables in Table 1.

Figure 1 shows the fiber attenuation in relation to both signal wavelength and ambient temperature variations based on both silica doped/fluoride glass fibers at Ge/Al dopant ratio of $7 \%$. With a temperature of $320 \mathrm{~K}$, the silica doped fiber attenuation at $1.3 \mu \mathrm{m}$ is $0.07 \mathrm{~dB} / \mathrm{km}$, while the fluoride glass fiber attenuation is $0.075 \mathrm{~dB} / \mathrm{km}$ at the same wavelength. With a temperature of $450 \mathrm{~K}$, the silica doped fiber attenuation at 1.3 $\mu \mathrm{m}$ is $0.9 \mathrm{~dB} / \mathrm{km}$, while the fluoride glass fiber attenuation is $0.987 \mathrm{~dB} / \mathrm{km}$ at the same wavelength. With a temperature of $320 \mathrm{~K}$, the silica doped fiber attenuation at $1.55 \mu \mathrm{m}$ is $0.02 \mathrm{~dB} / \mathrm{km}$, while the fluoride glass fiber attenuation is $0.025 \mathrm{~dB} / \mathrm{km}$ at the same wavelength. With a temperature of $450 \mathrm{~K}$, the silica doped fiber attenuation at $1.55 \mu \mathrm{m}$ is $0.2 \mathrm{~dB} / \mathrm{km}$, while the fluoride glass fiber attenuation is $0.265 \mathrm{~dB} / \mathrm{km}$ at the same wavelength. The silica doped/fluoride glass fibers have better performance at a signal wavelength of $1.55 \mu \mathrm{m}$ than the other operating wavelengths.

Table 1. Numerical variables for this study $[1,3,7,13,15]$.

\begin{tabular}{ll}
\hline \multicolumn{1}{c}{ Variables } & \multicolumn{1}{c}{ Value/unit } \\
\hline Temperature $(\mathrm{T})$ & $320 \mathrm{~K}-450 \mathrm{~K}$ \\
Room temperature $\left(\mathrm{T}_{0}\right)$ & $300 \mathrm{~K}$ \\
Refractive index difference $(\Delta \mathrm{n})$ & 0.001 \\
Fiber cable length $(\mathrm{L})$ & $10 \mathrm{~km}$ \\
Source linewidth $(\Delta \lambda)$ & $0.1 \mathrm{~nm}$ \\
Transmitter power $\left(\mathrm{PT}_{\mathrm{T}}\right)$ & $10 \mathrm{~mW}$ \\
Ge dopant ratio $(\mathrm{x})$ & $1 \%-7 \%$ \\
Aluminum dopant ratio $(\mathrm{y})$ & $1 \%-7 \%[20]$ \\
Fiber core radius & $2.5 \mu \mathrm{m}$ \\
Wavelength $(\lambda)$ & $1.3 \mu \mathrm{m}-1.65 \mu \mathrm{m}$ \\
\hline
\end{tabular}

Figure 2 indicates the fiber bandwidth variations against both Ge/Al dopant ratio and temperature variations based on both silica doped/fluoride glass fibers at a signal wavelength of $1.55 \mu \mathrm{m}$. Fluoride glass 
fiber bandwidth has $0.5 \mathrm{GHz}$ at an $\mathrm{Al}$ dopant ratio of $1 \%, 4 \mathrm{GHz}$ at $\mathrm{Al}$ dopant ratio of $4 \%$, and $32 \mathrm{GHz}$ at $\mathrm{Al}$ dopant ratio of $7 \%$ at a temperature of $320 \mathrm{~K}$.

Silica doped glass fiber bandwidth has $1 \mathrm{GHz}$ at a Ge dopant ratio of $1 \%, 8 \mathrm{GHz}$ at a Ge dopant ratio of $4 \%$, and $64 \mathrm{GHz}$ at a Ge dopant ratio of $7 \%$ at a temperature of $320 \mathrm{~K}$. Fluoride glass fiber bandwidth has $0.1 \mathrm{GHz}$ at an $\mathrm{Al}$ dopant ratio of $1 \%, 0.8 \mathrm{GHz}$ at an $\mathrm{Al}$ dopant ratio of $4 \%$, and $6.4 \mathrm{GHz}$ at an $\mathrm{Al}$ dopant ratio of $7 \%$ at a temperature of $450 \mathrm{~K}$. Silica doped glass fiber bandwidth has $0.4 \mathrm{GHz}$ at a Ge dopant ratio of $1 \%$, $3.2 \mathrm{GHz}$ at a $\mathrm{Ge}$ dopant ratio of $4 \%$, and $26.5 \mathrm{GHz}$ at a $\mathrm{Ge}$ dopant ratio of $7 \%$ at a temperature of $450 \mathrm{~K}$.

Figure 3 clarifies the received power variations against both Ge/Al dopant ratio and temperature variations based on both silica doped/fluoride glass fibers at a signal wavelength of $1.55 \mu \mathrm{m}$. Fluoride glass fibers received power has $7.765 \mathrm{~mW}$ at an $\mathrm{Al}$ dopant ratio of $1 \%, 8.54 \mathrm{Mw}$ at an $\mathrm{Al}$ dopant ratio of $4 \%$, and $9.56 \mathrm{~mW}$ at an $\mathrm{Al}$ dopant ratio of $7 \%$ at a temperature of $320 \mathrm{~K}$. Silica doped glass fibers received power has $7.89 \mathrm{~mW}$ at a Ge dopant ratio of $1 \%, 8.87 \mathrm{~mW}$ at a Ge dopant ratio of $4 \%$, and $9.765 \mathrm{~mW}$ at a Ge dopant ratio of $7 \%$ at a temperature of $320 \mathrm{~K}$. Fluoride glass fibers received power has $6.65 \mathrm{~mW}$ at an $\mathrm{Al}$ dopant ratio of $1 \%, 7.765 \mathrm{~mW}$ at an $\mathrm{Al}$ dopant ratio of $4 \%$, and $8.54 \mathrm{~mW}$ at an $\mathrm{Al}$ dopant ratio of $7 \%$ at a temperature of $450 \mathrm{~K}$. Silica doped glass fibers received power has $6.98 \mathrm{~mW}$ at a Ge dopant ratio of $1 \%, 3.27 .89 \mathrm{~mW}$ at a $\mathrm{Ge}$ dopant ratio of $4 \%$, and $8.8765 \mathrm{~mW}$ at a Ge dopant ratio of $7 \%$ at a temperature of $450 \mathrm{~K}$. The received power is upgraded with the increase of the dopant ratios of Ge/Al-based silica/fluoride glass fibers.

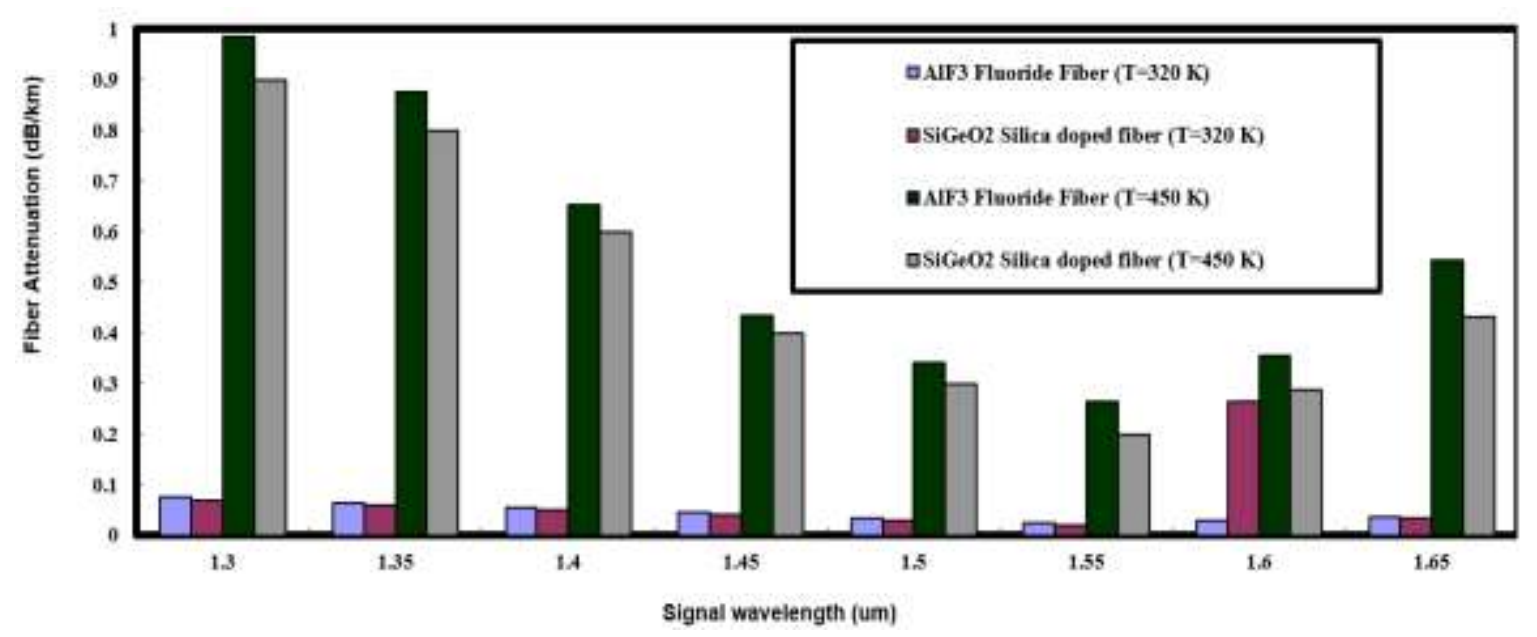

Figure 1. Fiber attenuation in relation to both signal wavelength and ambient temperature variations based on both silica doped/fluoride glass fibers at a Ge/Al dopant ratio of $7 \%$

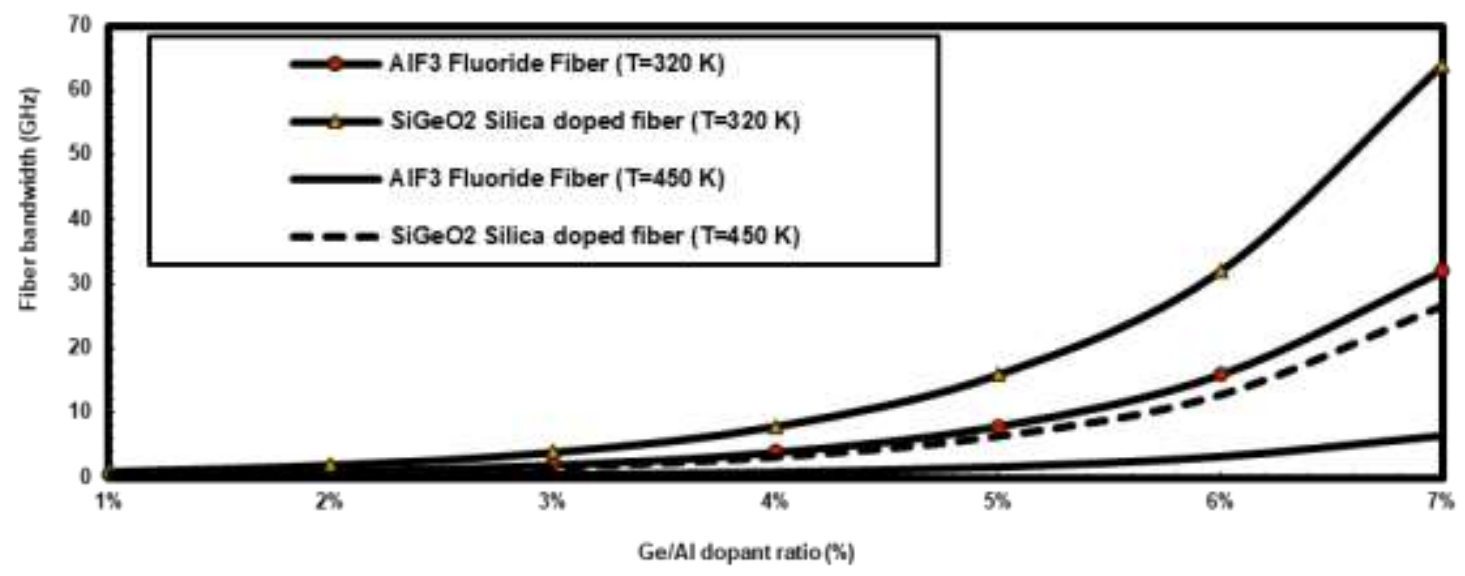

Figure 2. Fiber bandwidth variations against both Ge/Al dopant ratio and temperature variations based on both silica doped/fluoride glass fibers at a signal wavelength of $1.55 \mathrm{~m}$ 


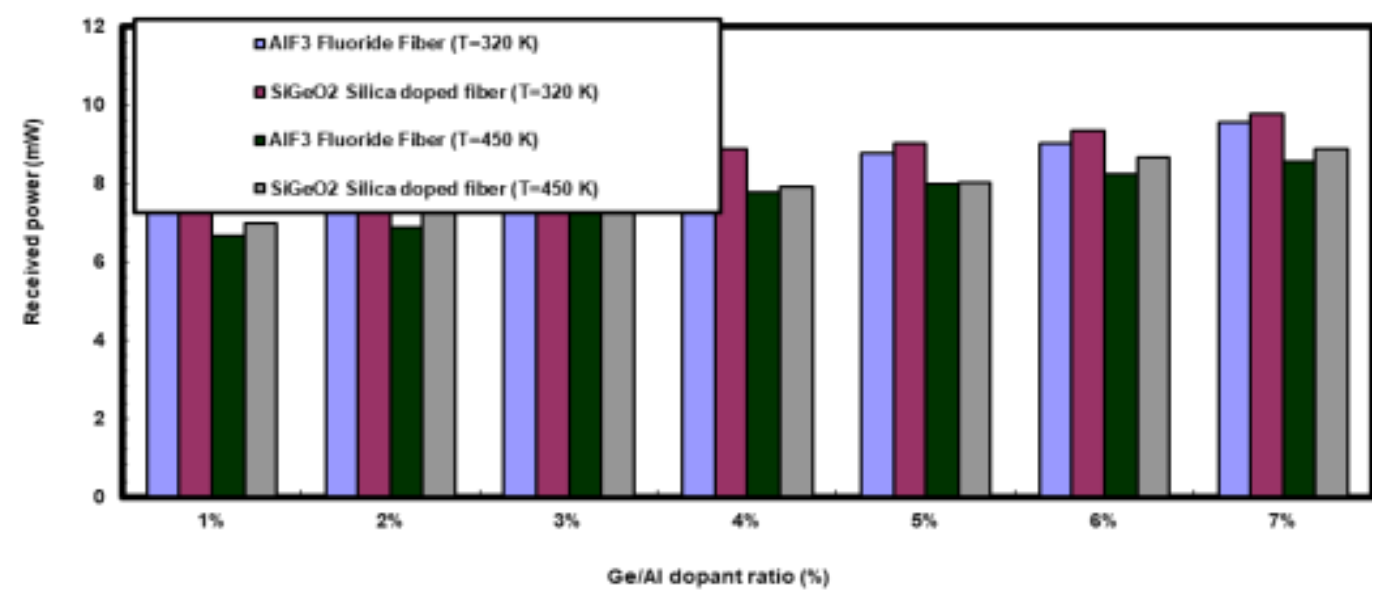

Figure 3. Received power variations against both $\mathrm{Ge} / \mathrm{Al}$ dopant ratio and temperature variations based on both silica doped/fluoride glass fibers at a signal wavelength of $1.55 \mu \mathrm{m}$

Figure 4 indicates the fiber bandwidth variations against temperature variations based on both silica doped/fluoride glass fibers at a signal wavelength of $1.55 \mu \mathrm{m}$ and a $\mathrm{Ge} / \mathrm{Al}$ dopant ratio of $7 \%$. The fluoride glass fiber bandwidth is $32 \mathrm{GHz}$ at $\mathrm{T}=320 \mathrm{~K}$, while the silica doped glass fiber bandwidth is $64 \mathrm{GHz}$ at the same temperature, where the fluoride glass fiber bandwidth is $8 \mathrm{GHz}$ at $\mathrm{T}=375 \mathrm{~K}$, while the silica doped glass fiber bandwidth is $16 \mathrm{GHz}$ at the same temperature. The fluoride glass fiber bandwidth is $0.5 \mathrm{GHz}$ at $\mathrm{T}=450 \mathrm{~K}$, while the silica doped glass fiber bandwidth is $1 \mathrm{GHz}$ at the same temperature. The fiber bandwidth decreases with the increase of temperature.

Figure 5 clarifies the received power variations against temperature variations based on both silica doped/fluoride glass fibers at a signal wavelength of $1.55 \mu \mathrm{m}$ and a $\mathrm{Ge} / \mathrm{Al}$ dopant ratio of $7 \%$. The fluoride glass fiber received power is $9.56 \mathrm{~mW}$ at $\mathrm{T}=320 \mathrm{~K}$, while the silica doped glass fibers received power is $9.765 \mathrm{~mW}$ at the same temperature, where the fluoride glass fiber received power is $8.43 \mathrm{~mW}$ at $\mathrm{T}=375 \mathrm{~K}$ and the silica doped glass fibers received power is $8.945 \mathrm{~mW}$ at the same temperature. The fluoride glass fiber received power is $6.744 \mathrm{~mW}$ at $\mathrm{T}=450 \mathrm{~K}$, while the silica doped glass fibers received power is $7.69 \mathrm{~mW}$ at the same temperature. The fiber received power decreases with the increase of temperature.

Figure 6 shows the fiber loss variations against temperature variations based on both silica doped/fluoride glass fibers at a signal wavelength of $1.55 \mu \mathrm{m}$ and a $\mathrm{Ge} / \mathrm{Al}$ dopant ratio of $7 \%$. The fluoride glass fiber loss is $0.025 \mathrm{~dB} / \mathrm{km}$ at $\mathrm{T}=320 \mathrm{~K}$, while the silica doped glass fibers loss is $0.02 \mathrm{~dB} / \mathrm{km}$ at the same temperature, where the fluoride glass fiber loss is $0.035 \mathrm{~dB} / \mathrm{km}$ at $\mathrm{T}=375 \mathrm{~K}$ and the silica doped glass fiber loss is $0.03 \mathrm{~dB} / \mathrm{km}$ at the same temperature. The fluoride glass fiber loss is $0.085 \mathrm{~dB} / \mathrm{km}$ at $\mathrm{T}=450 \mathrm{~K}$, while the silica doped glass fiber loss is $0.08 \mathrm{~dB} / \mathrm{km}$ at the same temperature. The fiber loss increases with the increase of temperature.

Figure 7 clarifies the fiber pulse broadening variations against temperature variations based on both silica doped/fluoride glass fibers at a signal wavelength of $1.55 \mu \mathrm{m}$ and a Ge/Al dopant ratio of $7 \%$. The fluoride glass fiber pulse broadening is $0.02 \mathrm{~ns}$ at $\mathrm{T}=320 \mathrm{~K}$, while the silica doped glass fiber pulse broadening is $0.01 \mathrm{~ns}$ at the same temperature, where the fluoride glass fiber pulse broadening is $0.08 \mathrm{~ns}$ at $\mathrm{T}=375 \mathrm{~K}$ and the silica doped glass fiber pulse broadening is $0.04 \mathrm{~ns}$ at the same temperature. The fluoride glass fiber pulse broadening is $0.6545 \mathrm{~ns}$ at $\mathrm{T}=450 \mathrm{~K}$, while the silica doped glass fiber pulse broadening is $0.32 \mathrm{~ns}$ at the same temperature. The fiber pulse broadening increases with the increase of temperature.

Figure 8 indicates the power loss percentage variations against temperature variations based on both silica doped/fluoride glass fibers at a signal wavelength of $1.55 \mu \mathrm{m}$ and a Ge/Al dopant ratio of $7 \%$. The fluoride glass fiber power loss percentage is $0.25 \%$ at $\mathrm{T}=320 \mathrm{~K}$, while the silica doped glass fiber power loss percentage is $0.2 \%$ at the same temperature, where the fluoride glass fiber power loss percentage is $1.32 \%$ at $\mathrm{T}=375 \mathrm{~K}$, while the silica doped glass fiber power loss percentage is $0.876 \%$ at the same temperature. The fluoride glass fiber power loss percentage is $4.87 \%$ at $\mathrm{T}=450 \mathrm{~K}$, while the silica doped glass fiber power loss percentage is $3.765 \%$ at the same temperature. The fiber power loss percentage increases with the increase of temperature. 


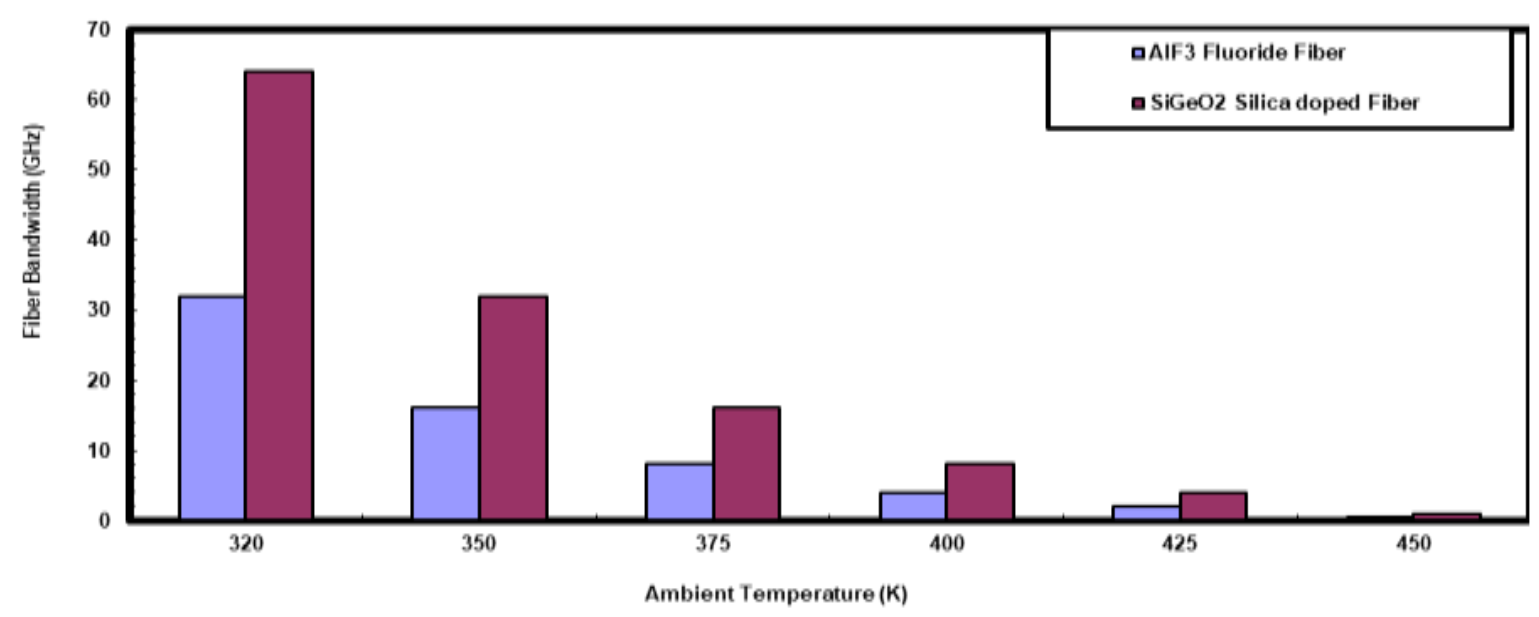

Figure 4. Fiber bandwidth variations against temperature variations based on both silica doped/fluoride glass fibers at a signal wavelength of $1.55 \mu \mathrm{m}$ and a $\mathrm{Ge} / \mathrm{Al}$ dopant ratio of $7 \%$

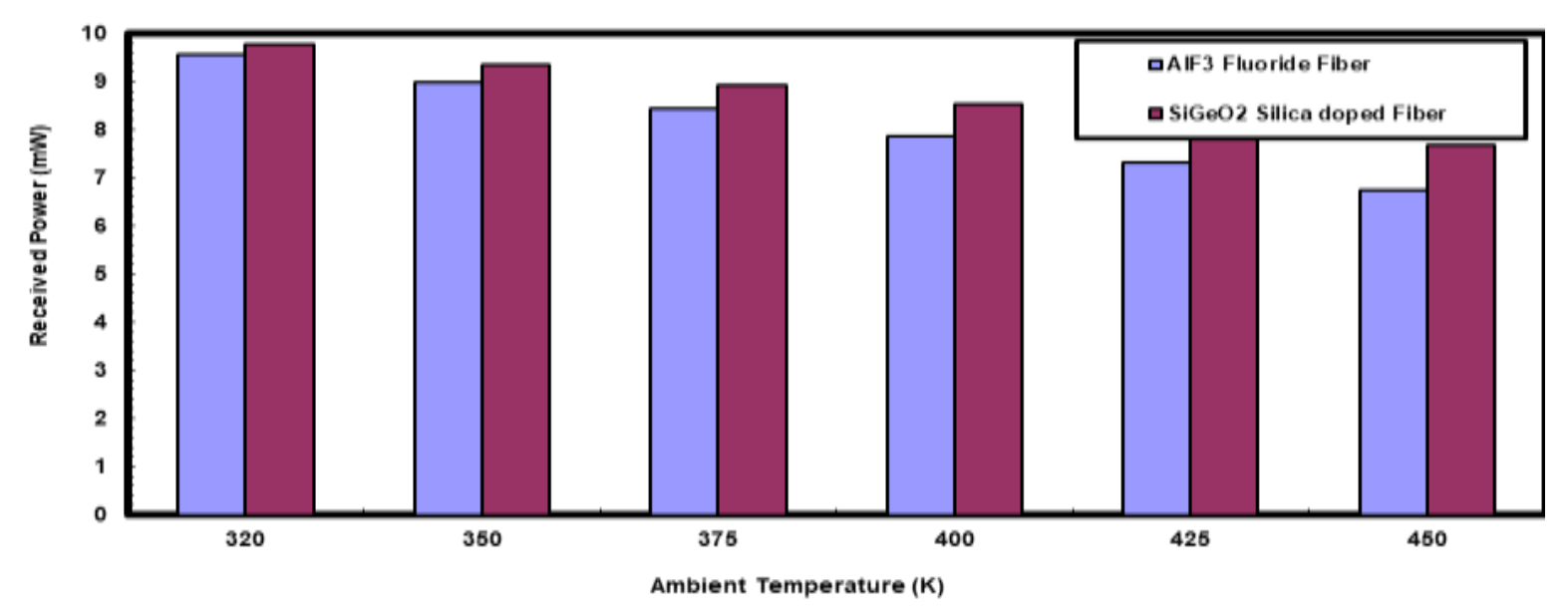

Figure 5. Received power variations against temperature variations based on both silica doped/fluoride glass fibers at a signal wavelength of $1.55 \mu \mathrm{m}$ and a $\mathrm{Ge} / \mathrm{Al}$ dopant ratio of $7 \%$

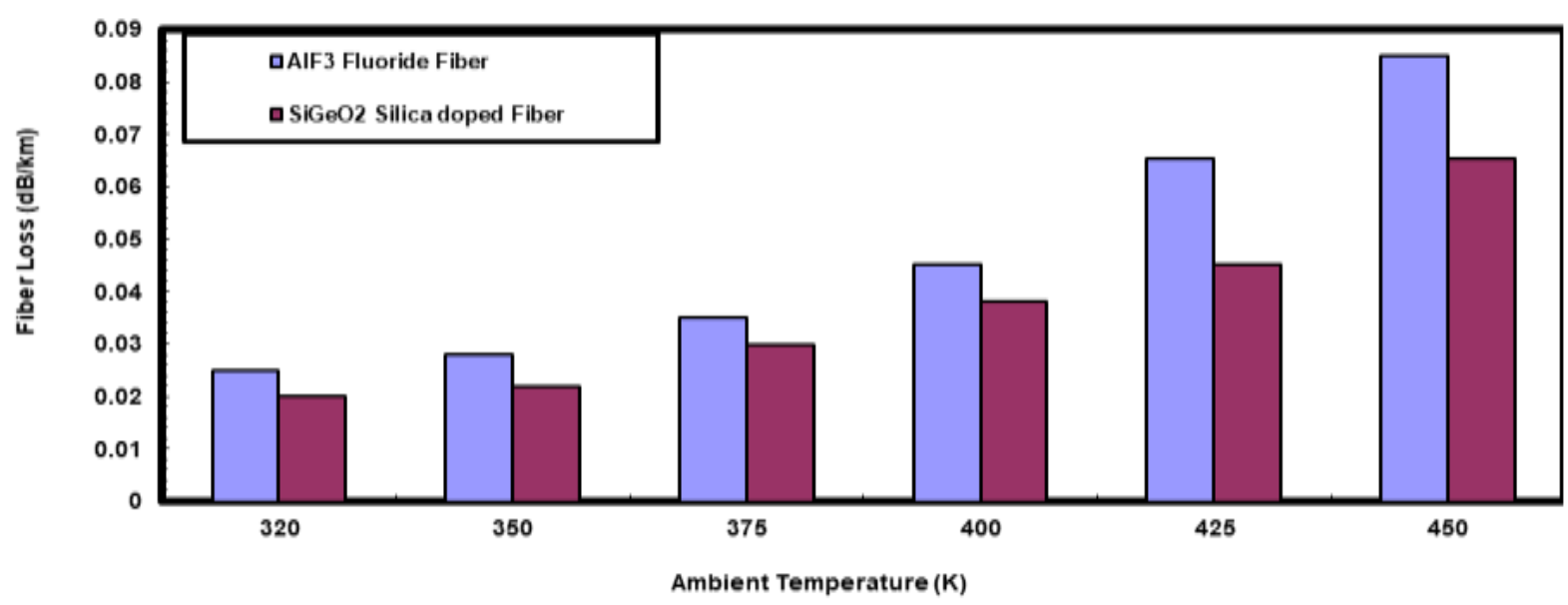

Figure 6. Fiber loss variations against temperature variations based on both silica doped/fluoride glass fibers at a signal wavelength of $1.55 \mu \mathrm{m}$ and a $\mathrm{Ge} / \mathrm{Al}$ dopant ratio of $7 \%$ 


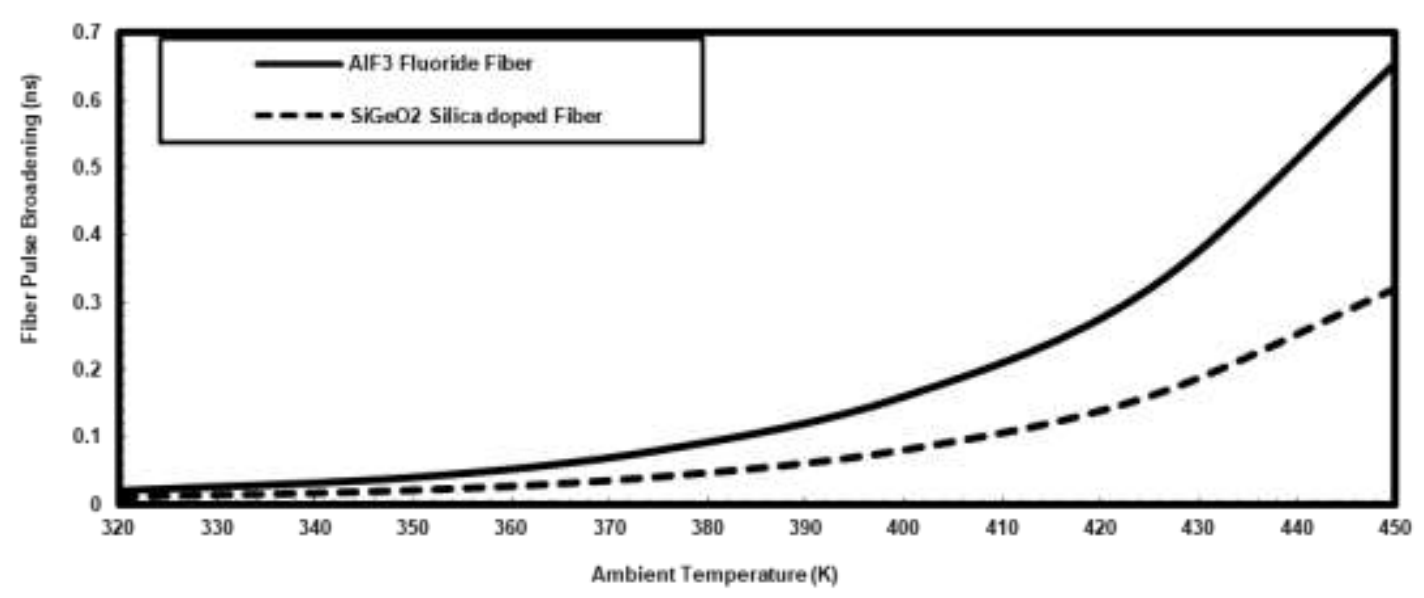

Figure 7. Fiber pulse broadening variations against temperature variations based on both silica doped/fluoride glass fibers at a signal wavelength of $1.55 \mu \mathrm{m}$ and a Ge/Al dopant ratio of $7 \%$

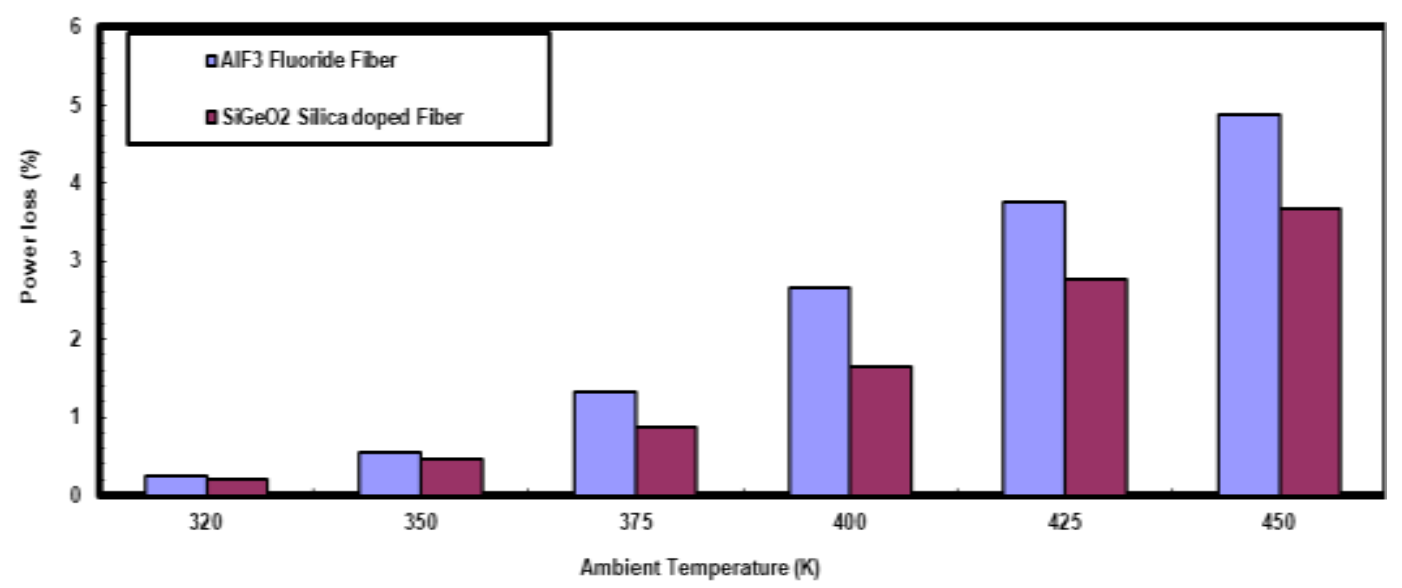

Figure 8. Power loss variations against temperature variations based on both silica doped/fluoride glass fibers at a signal wavelength of $1.55 \mu \mathrm{m}$ and a $\mathrm{Ge} / \mathrm{Al}$ dopant ratio of $7 \%$

\section{CONCLUSION}

This study has clarified the performance signature of silica doped/fluoride glass fibers in fiber-optic systems for propagation distances up to $10 \mathrm{~km}$. The study implies that the positive effects of adding dopants of $\mathrm{Ge} / \mathrm{Al}$ to silica doped/fluoride glass fibers is to reduce the fiber loss, power loss, and dispersion effects. The increase of an ambient temperature has negative effects on the performance of both fibers. The power loss and fiber pulse broadening increase with the increase of temperature, which results in the decrease of fiber bandwidth and the signal power received. Silica doped fibers have presented better performance than fluoride fibers at the same dopant ratios and ambient temperature variations. The performances of both silica doped and fluoride fiber performance are upgraded with a dopant ratio of 7\%, with room temperature at 300 $\mathrm{K}$ and signal wavelength employment at $1.55 \mu \mathrm{m}$.

\section{REFERENCES}

[1] Ahmed Nabih Zaki Rashed, et al., "The effect of using different materials on erbium-doped fiber amplifiers for indoor applications," Results in Physics, vol. 15, p. 102650, 2019.

[2] Ahmed Nabih Zaki Rashed, et al., "Optical communication transmission systems improvement based on chromatic and polarization mode dispersion compensation simulation management," Optik Journal, vol. 207, p. $163853,2020$.

[3] J. W. Fleming, "Dispersion in GeO2-SiO2 glasses," Applied Optics, vol. 23, no. 24, pp. 4488-4493, 1984. 
[4] H. Tokiwa, and Y. Mimura, "Ultra-low loss fluorida glass single mode fiber design," J. Lightwave Technol., vol. 4, no. 8, pp. 1260-1266, 1986.

[5] Y. Okamura, and S. Yamamato, "Ultra-Low loss single mode fiber design for 2.5-6 $\mu \mathrm{m}$ band absorption," Applied Optics, vol. 22, no. 19, pp. 3098-3101, 1983.

[6] Ahmed Nabih Zaki Rashed, et al., "A comparative study of the performance of graded index per-fluorinated plastic and alumino silicate optical fibers in internal optical interconnections," Optik Journal, vol. 127, no. 20, pp. 9259-9263, 2016.

[7] S. Mitachi and T. Miyashita, "Refractive Index Dispersion for BaF2-GdF3-ZrF4-AlF3 Glasses," Applied Optics, vol. 22, no. 16, pp. 2419-2425, 1983.

[8] S. M. Nagia, et al., "Fluoride release and recharge of enhanced resin modified glass monomer at different time intervals," Future Dental Journal, vol. 4, no. 2, pp. 221-222, 2018.

[9] F. Vendittia, et al., "Fluorides decontamination by means of aluminum polychloride based commercial coagulant," J. of Water Process Engineering, vol. 26, pp. 182-186, 2018.

[10] W. J. Tomlinson and R. H. Stolen, "Nonlinear phenomena in optical fibers," IEEE Comm. Magazine, vol. 26, no. 4, pp. 36-44, 1988.

[11] S. S. Walker, "Rapid modelling and estimation of total spectral loss in optical fibers," J. Lightwave Technol., vol. 4, no. 8, pp. 1125-1137, 1986.

[12] H. E. H. Ahmed, et al., "On the propagation characteristics of fluoride and germania doped optical fibers," Ain Shams Univ. Eng. Bulletin, vol. 27, no. 4, pp.241-255, 1992.

[13] K. Kitayama, et al., "Design Considerations for the Structural Optimization of a Single Mode Fiber", J. Lightwave Technol., vol. 1, no. 2, pp. 363-369, 1983.

[14] D. Wood, "Constraints on the bit rates in direct detection optical communication systems using linear or soliton pulses," J. Lightwave Technol., vol. 8, no. 7, pp. 1097-1106, 1990.

[15] R. Sanjari and M. Pourmahyabadi, "Design of single mode photonic crystal fiber with outstanding characteristics of confinement loss and chromatic dispersion over S and L communication band," Iranian Journal of Electrical \& Electronic Engineering, vol.12, no.1, pp. 29-34, 2016.

[16] Ahmed Nabih Zaki Rashed, et al., "An Accurate Model for Chromatic Dispersion in Optical Fibers under Radiation and Thermal Effects," International Journal of Advanced Research in Computer Engineering \& Technology (IJARCET), vol. 2, no.10, pp. 2646-2654, 2013.

[17] Ahmed Nabih Zaki Rashed, et al., "Performance Signature of Optical Fiber Communications Dispersion Compensation Techniques for the Control of Dispersion Management," Journal of Optical Communications, 2019, [Online] Available: https://doi.org/10.1515/joc-2019-0021.

[18] Ahmed Nabih Zaki Rashed, et al., "Ultra high transmission capacity based on optical first order soliton propagation systems," Results in Physics, vol. 12, pp. 512-513, 2019.

[19] IS Amiri, et al., "Mathematical model analysis of dispersion and loss in photonic crystal fibers," Journal of Optical Communications, 2019, [Online]. Available: https://doi.org/10.1515/joc-2019-0052.

[20] M. Poulain and A. Soufiane, "Fluoride Glasses: Synthesis and Properties," Brazilian Journal of Physics, vol. 22, no. 3, pp. 205-217, 1992.

[21] IS Amiri, et al., "Chirped large mode area photonic crystal modal fibers and its resonance modes based on finite element technique," Journal of Optical Communications, 2019, [Online]. Available: https://doi.org/10.1515/joc2019-0146.

[22] IS Amiri, et al., "Comparative simulation of thermal noise effects for photodetectors on performance of long-haul DWDM optical networks," Journal of Optical Communications, [Online]. Available: https://doi.org/10.1515/joc-2019-0152.

[23] IS Amiri, et al., "Single wide band traveling wave semiconductor optical amplifiers for all optical bidirectional wavelength conversion," Journal of Optical Communications, [Online]. Available: https://doi.org/10.1515/joc-2019-0168.

[24] IS Amiri, et al., "Influence of loading, regeneration and recalling elements processes on the system behavior of all optical data bus line system random access memory," Journal of Optical Communications, 2019, [Online]. Available: https://doi.org/10.1515/joc-2019-0163.

[25] IS Amiri, et al., "Comparative simulation study of multi stage hybrid all optical fiber amplifiers in optical communications," Journal of Optical Communications, 2020, [Online]. Available: https://doi.org/10.1515/joc-2019-0132.

[26] S. E. Miller and I. P. Kaminow, Eds., Optical Fiber Telecommunications II, Academic Press, 1988.

[27] D. Marcuse, Principle of optical fiber measurements, Academic Press, 1981.

\section{BIOGRAPHIES OF AUTHORS}

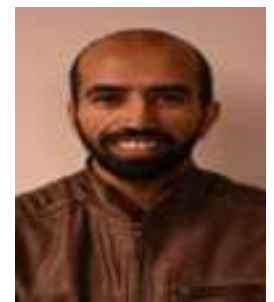

Dr. Aadel Alatwi was born in Tabuk, Saudi Arabia, in 1980. He received the B.S. degree from King Abdul-Aziz University, Jeddah, Saudi Arabia, in 2004, the M.S. and Ph.D degrees from Griffith University, Brisbane, Australia, in 2008 and 2018 respectively, both in communication engineering. He is currently assistant professor in the School of Engineering at Tabuk University, Tabuk, Saudi Arabia. His current research interests include speech coding, speech and speaker recognition, speech enhancement, face recognition, image coding, pattern recognition and artificial neural networks. His email: aadel.alatwi@ut.edu.sa. 


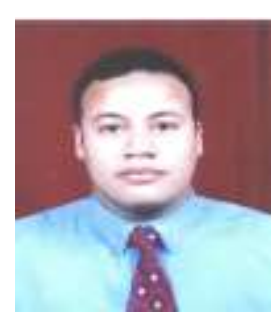

Assoc. Prof. Ahmed Nabih Zaki Rashed was born in Menouf city, Menoufia State, Egypt country in 23 July 1976. Received the B.Sc., M.Sc., and Ph.D. scientific degrees in the Electronics and Electrical Communications Engineering Department from Faculty of Electronic Engineering, Menoufia University in 1999, 2005, and 2010 respectively. Currently, his job carrier is a scientific lecturer in Electronics and Electrical Communications Engineering Department, Faculty of Electronic Engineering, Menoufia university, Menouf. Postal Menouf city code: 32951, EGYPT. His scientific master science thesis has focused on polymer fibers in optical access communication systems. Moreover, his scientific $\mathrm{Ph}$. D. thesis has focused on recent applications in linear or nonlinear passive or active in optical networks. His interesting research mainly focuses on transmission capacity, a data rate product and long transmission distances of passive and active optical communication networks, wireless communication, radio over fiber communication systems, and optical network security and management. He has published more than 220 published scientific papers in international journals and conferences. He has published many high scientific research papers in high quality and technical international journals in the field of advanced communication systems, optoelectronic devices, and passive optical access communication networks. His areas of interest and experience in optical communication systems advanced optical communication networks, wireless optical access networks, analog communication systems, optical filters and Sensors. As well as he is editorial board member in high academic scientific International research Journals. Moreover, he is a reviewer member in high impact scientific research international journals in the field of electronics, electrical communication systems, optoelectronics, information technology and advanced optical communication systems and networks. His personal electronic mail ID (Email:ahmed_733@yahoo.com). His published paper under the title "High reliability optical interconnections for short range applications in high performance optical communication systems" in Optics and Laser Technology, Elsevier Publisher has achieved most popular download articles in 2013. 